\title{
The use of platelet-rich plasma gel in superficial parotidectomy
}

\author{
L'utilizzo del platelet-rich plasma gel nella parotidectomia esofacciale \\ E. RICCI, G. RIVA, F. DAGNA, A.L. CAVALOT \\ Otorhinolaryngology Division, Santa Croce Hospital, Moncalieri, Italy
}

\section{SUMMARY}

Platelet-rich plasma (PRP) gel has been used in several conditions to enhance wound healing processes. The aim of this retrospective study was to evaluate clinical outcomes in patients who underwent superficial parotidectomy with and without the use of PRP gel at the surgical field. Fifty-nine patients underwent superficial parotidectomy with preservation of the facial nerve for benign tumours. In 21 cases, PRP gel was added on the remaining parotid gland and facial nerve branches. Clinical characteristics, complications, length of hospitalisation and duration of the drainage tube maintenance were recorded. The median duration of drainage tube maintenance was 2 and 3 days, and median hospital stay was 3 and 4 days in the PRP-group and non-PRP-group, respectively. Facial palsy and salivary complications (sialocele and salivary fistula) were more frequent in the non-PRP-group. The use of PRP gel seems to have positive effects on clinical outcomes in superficial parotidectomy for benign tumours. It represents an efficient and low-cost adjunct that can lower complications.

KEY WORDS: Parotidectomy $\bullet$ Platelet-rich plasma $\bullet$ Platelets $\bullet$ Salivary tumours $\bullet$ Sialocele

\section{RIASSUNTO}

Il Platelet-rich Plasma (PRP) gel viene utilizzato in numerose situazioni per favorire i processi di guarigione. Lo scopo di questo studio retrospettivo è valutare $i$ risultati clinici dell'utilizzo del gel piastrinico nella parotidectomia esofacciale. Cinquantanove pazienti sono stati sottoposti a parotidectomia esofacciale con preservazione del nervo facciale per tumore benigno. In 21 casi il gel piastrinico è stato aggiunto sui rami del nervo facciale e sul tessuto ghiandolare rimanente. Sono state registrate le caratteristiche cliniche, le complicanze post-operatorie, la durata dell'ospedalizzazione e di mantenimento del drenaggio. La durata mediana di mantenimento del drenaggio è stata 2 giorni nel gruppo trattato con il PRP gel e 3 giorni negli altri pazienti. La durata mediana di ospedalizzazione è stata rispettivamente 3 e 4 giorni. La paralisi del nervo facciale e le complicanze salivari (scialocele e fistola salivare) sono state più frequenti nel gruppo non trattato con il gel piastrinico. L'utilizzo del gel piastrinico sembra avere effetti positivi sui risultati clinici nella parotidectomia esofacciale per tumoure benigno. Rappresenta una procedura efficace e a basso costo, che è in grado di ridurre le complicanze.

PAROLE CHIAVE: Parotidectomia $\bullet$ Platelet-rich plasma $\bullet$ Piastrine $\bullet$ Tumoure di ghiandola salivare $\bullet$ Scialocele

\section{Introduction}

Benign tumours represent the majority $(80-90 \%)$ of salivary gland tumours. Pleomorphic adenomas and Warthin tumours are the main benign parotid gland tumours. Most $(80 \%)$ occur in the superficial lobe of the parotid gland, laterally to facial nerve branches ${ }^{1}$.

Superficial parotidectomy is the elective treatment for benign lesions of the superficial lobe in order to lower the incidence of relapse. Impaired facial nerve function, sialocele and salivary fistula represent the main complications of superficial parotidectomy. In particular, sialocele is a collection of saliva under the surgical site, as a result of salivary leakage from the remaining gland parenchyma. The incidence of sialocele varies from 5\% to $39 \%$ of patients after partial parotidectomy ${ }^{2-6}$. Its treatment is generally conservative, with aspiration of the collected saliva and pressure dressings ${ }^{3}$. Salivary fistula represents a rare complication of sialoceles and may persist for weeks or months. Therefore, salivary complications can prolong post-operative dressings, with an increase in healthcare costs and worsening of the quality of life ${ }^{3}$.

In a recent randomised controlled study, Scala et al. used platelet-rich plasma (PRP) gel at the surgical field in superficial parotidectomy to reduce post-operative complications, with a particular focus on preserving facial nerve functionality and improving cosmetic results ${ }^{7}$. Plateletrich plasma and PRP gel have been used in several conditions to enhance wound healing processes. During wound healing, platelet-derived growth factors can stimulate tissue repair and cell proliferation, influence extracellular 
matrix deposition, and support cell proliferation and differentiation ${ }^{89}$. Thus, in superficial parotidectomy PRP gel may be useful for reducing post-operative sialoceles.

The aim of this retrospective study was to evaluate clinical outcomes in 59 patients who underwent superficial parotidectomy with and without the use of PRP gel at the surgical field.

\section{Materials and methods}

Between January 2012 and June 2017, 59 consecutive patients with a benign tumour of the parotid gland underwent superficial parotidectomy at our Division. Twenty-one of 59 patients were treated between January 2015 and June 2017. In these patients, PRP gel was added at the surgical field. Subjects with malignant tumour of the parotid gland or those who underwent total parotidectomy were excluded from the study. PRP gel was not used in the suspicion of malignant disease, because of the high concentration of growth factors in PRP gel. Written informed consent was obtained by each patient. The study complies with the Declaration of Helsinki for Medical Research involving Human Subjects. Due to the retrospective nature of this study, it was granted an exemption in writing by the Institutional Review Board.

Each patient underwent ultrasound imaging of the parotid glands and pre-operative Fine-Needle Aspiration Cytology (FNAC) for diagnosis. Clinical characteristics, outcomes, and complications were recorded (Group A: without PRP gel, 38 patients; Group B: with PRP gel, 21 patients). In particular, our attention focused on post-operative facial palsy, sialocele and salivary fistula. We recorded the length of hospitalisation and duration of drainage tube maintenance.

All patients underwent superficial parotidectomy with preservation of the facial nerve. In group B, PRP gel was added on the remaining parotid gland and facial nerve branches. In 8 of 38 patients in group A, a haemostatic agent (Tachosil, Aventis Behring GmbH, Marburg/Lahn, Germany) was added at the surgical field. A drainage tube was placed in all patients.

PRP was procured by collecting venous blood with two appropriate tubes (10 ml RegenCT tubes, Regent Lab SA, Le Mont-sur-Lausanne, Switzerland) usually before starting the surgical operation. Each tube contained $1 \mathrm{ml}$ of sodium citrate as anticoagulant. They were carefully turned upside down several times to homogenise blood with anticoagulant. The tubes were immediately centrifuged at 3,100 rpm for 9 min (Regent Lab SA centrifuge, Le Mont-sur-Lausanne, Switzerland). Then, $1 \mathrm{ml}$ of calcium gluconate was added to the content of the tubes. Another centrifugation at 3,100 rpm for 9 minutes was performed. The tubes were placed in the centrifuge at room temperature until the PRP gel was used. After removal of superficial parotid gland and adequate haemostasis, PRP gel was carefully pulled out with sterile surgical forceps, separating from the part that remains in the tubes. It was applied on the remaining parotid gland and the branches of the facial nerve. The drainage tube was put on the PRP gel (Fig. 1).

All statistical analyses were carried out using Statistical Package for Social Sciences (SPSS), version 20.0. A descriptive analysis of all data was performed and reported as means or percentages and standard deviations. MannWhitney $\mathrm{U}$ test was used to compare continuous variables. A p value less than 0.05 was considered significant.

\section{Results}

Mean age of patients was $53.58 \pm 14.38$ years (range 1979 years) in group A and $50.13 \pm 17.19$ years (range 18-
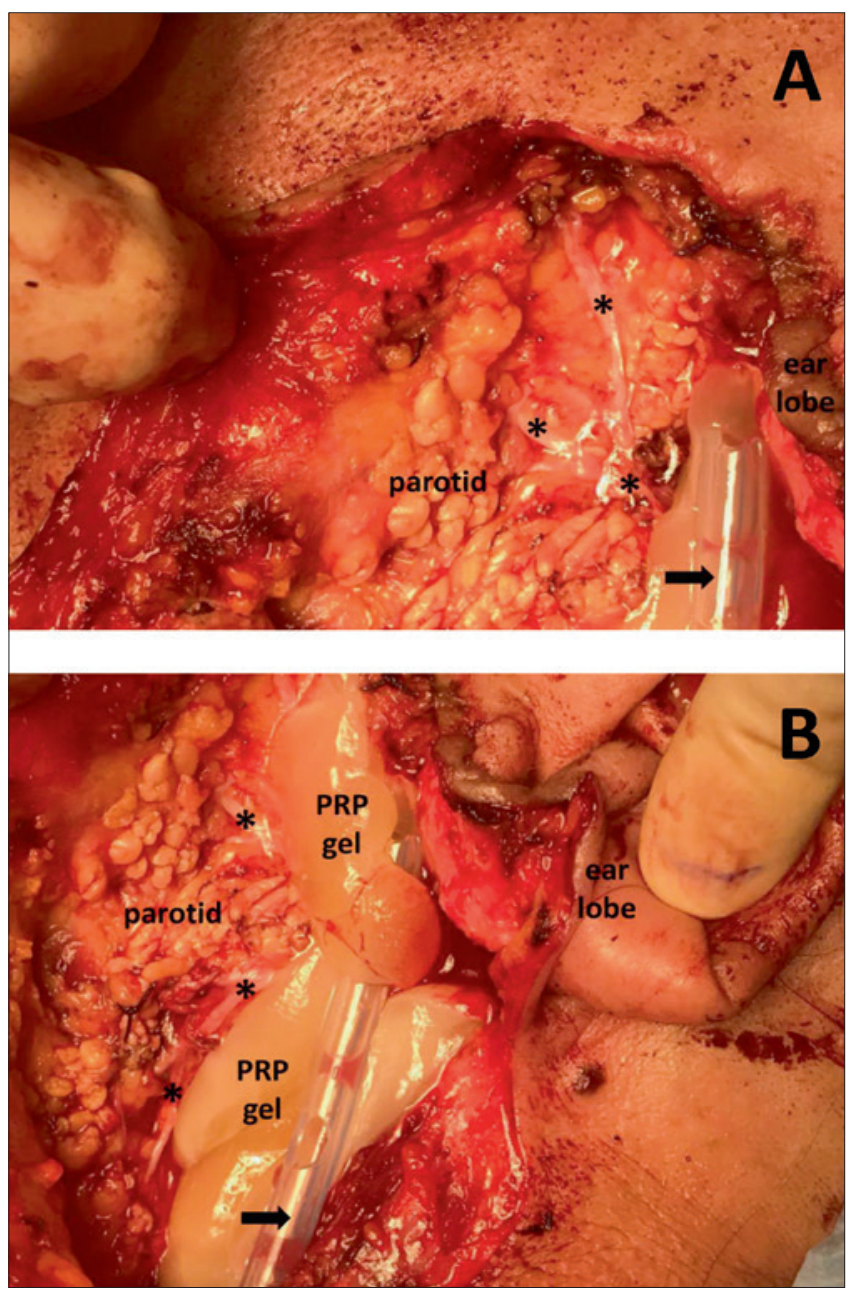

Fig. 1. (A) Group A: the drainage tube (arrow) is put on the facial nerve and its branches (asterisks). (B) Group B: the PRP gel is applied on the remaining parotid gland and the branches of the facial nerve (asterisks), under the drainage tube (arrow). 
72 years) in group B. The male/female ratio was $12 / 9$ in group A and 18/20 in group B. Definitive histology was pleomorphic adenoma in 17 and 11 patients and Warthin's tumour in 21 and 10 patients, respectively, in groups A and $B(p>0.05)$. Thus, there was no significant difference in clinical characteristics between groups. No patients had pre-operative facial palsy. No patient had bilateral parotid tumour. Mean follow-up was $18.12 \pm 7.36$ months for group A and $15.07 \pm 5.64$ months for group B.

The median duration of drainage maintenance was 3 days (range 2-5) in group A and 2 days (range 2-4) in group B $(\mathrm{p}<0.05)$. The median hospital stay was 4 days (range 3-7 days) in group $A$ and 3 days (range 2-5 days) in group $\mathrm{B}(\mathrm{p}<0.05)$.

Immediate post-operative facial palsy was observed in 4 $(10.5 \%)$ and $2(9.5 \%)$ cases, respectively, in groups A and B ( $p>0.05)$. In group A, 2 additional cases of facial palsy occurred after 24 hours, resulting in 6 patients $(15.7 \%)$ with facial palsy. All facial palsies were temporary and resolved within 2 months.

Sialocele occurred in 7 patients $(18.4 \%)$ in group A and in 2 patients $(9.5 \%)$ in group B $(\mathrm{p}>0.05)$. In group A, one sialocele occurred when haemostatic agent was used. Only one salivary fistula was observed in group A. Salivary complications were treated with pressure dressings. Recovery from salivary complications occurred within 1 month in all cases. No symptomatic Frey's syndrome and keloids occurred in either group. No side effects due to PRP gel were recorded. No patient had relapse.

\section{Discussion}

Superficial parotidectomy represents the main treatment for most parotid gland lesions. In particular, it has become mandatory for benign tumours of the superficial lobe. Facial palsy, sialoceles, salivary fistulae, keloids and Frey's syndrome are the most common complications ${ }^{34}$. The incidence of sialoceles is highly variable among studies, ranging from $5 \%$ to $39 \%$ of patients after superficial parotidectomy ${ }^{2-6}$. This large variance in incidence may be due to the surgery technique, histology of the tumor, or to definition of a clinically significant collection. Performing partial superficial parotidectomies can led to an increase in the incidence of sialocele ${ }^{3}$. However, sialocele formation seems to be an unpredictable event.

Sialoceles provoke delay in wound healing and sometimes the formation of a salivary fistula. Methods to prevent sialoceles include prolonged drainage use and intra-operative application of tissue glue ${ }^{1011}$. Persistent sialoceles can be treated by repeated needle aspiration, pressure dressings, exploration of the wound, oral anticholinergics and botulinum toxin injection ${ }^{12}$. Herbert et al. demonstrated that the use of absorbable haemostatic material, placed within the wound to protect the facial nerve branches from drainage irritation, provoked a 6-fold increase in the risk of sialocele formation ${ }^{2}$. In our study, sialocele occurred in $12.5 \%$ of patients with haemostatic agent, similar to the overall percentage in group A (18.4\%). Therefore, the confounding effect of the haemostatic agent in evaluating the results of the study can be considered absent.

Temporary impairment of the entire facial nerve or its branches occurs in $5 \%$ to $65 \%$ of cases ${ }^{4}$. Suction by surgical drainage may explain a percentage of facial nerve palsies that appear in the post-operative period.

PRP and PRP gel are widely used in different areas of regenerative medicine to enhance wound healing processes. The reason for their clinical use lies in the abundance of growth factors contained in concentrated platelets that promote soft and hard tissue regeneration, and allows restoration of homeostasis ${ }^{9}$. In particular, they are used for the treatment of chronic wounds, such as diabetic foot and leg ulcers ${ }^{13}$. The use of PRP accelerates healing in dental implant surgery, orthopaedic surgery, muscle and tendon repair and ocular surgery. Moreover, PRP can reduce neurological and neuropathic pain associated with injuries ${ }^{9}$. PRP consists of autologous plasma with a platelet concentration 5-fold higher than basal level ${ }^{14-16}$. If a platelet activator, such as calcium, is added to PRP, platelet aggregation occurs and PRP is transformed into a PRP gel.

To our knowledge, only one study with a small sample analysed the efficacy of PRP gel in superficial parotidectomy for benign tumours. Scala et al. performed a controlled randomised trial on 20 patients who underwent superficial parotidectomy. 8 of 20 patients had PRP gel added at the surgical field. They found a positive trend in the PRP-group regarding median serum drainage, facial nerve impairment, Frey's syndrome and keloid formation. Hospital stay was not different in the two groups ${ }^{7}$. The limits of the study by Scala et al. were the small sample and lack of analysis of salivary complications, which could be the main target of PRP use.

We performed a retrospective analysis of patients who underwent superficial parotidectomy for benign tumours, with or without PRP gel added at the surgical field. At our Division, PRP gel was systematically used in superficial parotidectomy from January 2015, with the consent of patients. It was applied on the remaining parotid gland and the branches of the facial nerve in order to reduce drainage suction on the nerves and decrease the incidence of salivary complications. Our study suggests a positive effect of PRP gel on clinical outcomes, with no side effects detected. In particular, sialocele formation was halved in the PRP group, with a consequent reduction of 
the need for pressure dressings. No salivary fistula was observed after the use of PRP gel. Although the occurrence of sialocele is more frequent after pleomorphic adenoma, it does not represent a bias in our study because there were no significant differences in histological types between groups. Concerning post-operative facial palsy, there was a reduction in delayed onset in the PRP group, probably due to less suction on the branches of the facial nerve by the drainage tube. The absence of symptomatic Frey's syndrome in both groups could be ascribed to the brief follow-up time. The median duration of drainage tube maintenance and median hospital stay were significantly lower in the PRP group. All these positive findings may lead to a decrease in healthcare costs ${ }^{17}$. Indeed, preparation of PRP gel is an easy and lowcost adjunct. One tube of PRP costs $€ 25$, while haemostatic agents are more expensive; e.g. Tachosil (Aventis Behring $\mathrm{GmbH}$, Marburg/Lahn, Germany) costs $€ 370$. Moreover, costs are also reduced because of the shortening of hospital stay. Since median hospital stay was reduced by one day, the economic savings was about $€ 2000$.

The limits of our study are the small number of patients and its retrospective nature. However, the two groups that were compared were similar in pre-operative clinical characteristics. Moreover, this is the first study on the use of PRP gel in superficial parotidectomy with large samples.

\section{Conclusions}

The use of PRP gel seems to have positive effects on clinical outcomes in superficial parotidectomy for benign tumours. Moreover, it represents an efficient and low-cost procedure that can lower complications. Further randomised studies with larger samples are necessary to better define the role of platelet concentrates in parotid surgery.

\section{Conflict of interest statement}

None declared.

\section{References}

1 Barnes L, Eveson JW, Reichart P, et al. Pathology and genetics. Head and neck tumours. World Health Organization classification of tumours. Lyon: IARC Press; 2005.
2 Herbert AA, Morton RP. Sialocele after parotid surgery: assessing the risk factors. Otolaryngol Head Neck Surg 2012;147:489-92. https://doi.org/10.1177/0194599812442043

3 Witt RL. The incidence and management of siaolocele after parotidectomy. Otolaryngol Head Neck Surg 2009;140:871-4. https://doi. org/10.1016/j.otohns.2009.01.021

4 Bova R, Saylor A, Coman B. Parotidectomy: review of treatment and outcomes. ANZ J Surg 2004;74:563-8. https://doi.org/10.1111/ j.1445-2197.2004.02988.x

5 Klintworth N, Zenk J, Koch M, et al. Postoperative complications after extracapsular dissection of benign parotid lesions with particular reference to facial nerve function. Laryngoscope 2010;3:484-90. https://doi.org/10.1002/lary.20801

6 Upton D, McNamar J, Connor N, et al. Parotidectomy: ten year review of 237 cases at a single institution. Otolaryngol Head Neck Surg 2007;136:788-92. https://doi.org/10.1016/j.otohns.2006.11.037

7 Scala M, Mereu P, Spagnolo F, et al. The use of platelet-rich plasma gel in patients with mixed tumour undergoing superficial parotidectomy: a randomized study. In vivo 2014;28:121-4.

8 De Pascale MR, Sommese L, Casamassimi A, et al. Platelet derivatives in regenerative medicine: an update. Transfus Med Rev 2015;29:52-61. https://doi.org/10.1016/j.tmrv.2014.11.001

9 Piccin A, Di Pierro AM, Canzian L, et al. Platelet gel: a new therapeutic tool with great potential. Blood Transfus 2017;15:333-40. https://doi.org/10.2450/2016.0038-16

10 Conboy P, Brown D. Use of tissue sealant for day surgery parotidectomy. J Otolaryngol 2008;37:208-11.

11 Maharaj M, Diamond C, Williams D, et al. Tisseel to reduce postparotidectomy wound drainage: randomized, prospective, controlled trial. J Otolaryngol 2006;35:36-9.

12 Ragona R, Blotta P, Pastore A, et al. Management of parotid sialocele with botulinum toxin. Laryngoscope 1999;109:1344-6. https://doi.org/10.1097/00005537-199908000-00032

13 Akingboye AA, Giddins S, Gamston P, et al. Application of autologous derived-platelet rich plasma gel in the treatment of chronic wound ulcer: diabetic foot ulcer. J Extra Corpor Technol 2010;42:20-9.

14 Moreno R, Gaspar Carreño M, Jiménez Torres J, et al. Methods to obtain platelet-rich plasma and osteoinductive therapeutic use. Farm Hosp 2015;39:130-136. https://doi.org/10.7399/fh.2015.39.3.7998

15 Crovetti G, Martinelli G, Issi M, et al. Platelet gel for healing cutaneous chronic wounds. Transfus Apher Sci 2004;30:145-51. https:// doi.org/10.1016/j.transci.2004.01.004

16 Kuffler DP. Platelet-rich plasma promotes axon regeneration, wound healing, and pain reduction: fact or fiction. Mol Neurobiol 2015;52:990-1014. https://doi.org/10.1007/s12035-015-9251-x

17 Meccariello G, Montevecchi F, D’Agostino G, et al. Surgical site infections after parotidectomy: management and benefits of an antibiotic prophylaxis protocol. Acta Otorhinolaryngol Ital 2019;39:13944. https://doi.org/10.14639/0392-100X-1768

Received: February 3, 2018 - Accepted: May 17, 2018

How to cite this article: Ricci E, Riva G, Dagna F, et al. The use of platelet-rich plasma gel in superficial parotidectomy. Acta Otorhinolaryngol Ital 2019;39:363-366. https://doi.org/10.14639/0392-100X-2093

Address for correspondence: Giuseppe Riva, Otorhinolaryngology Division, Santa Croce Hospital, piazza Ferdinando 3 , 10124 Moncalieri (TO), Italy. Tel. +39 011 6930255. Fax +39011 05899884. E-mail: giuseppe.riva84@ gmail.com

This is an open access article distributed in accordance with the Creative Commons Attribution Non Commercial (CC BY-NC 4.0) license, which permits others to distribute, remix, adapt, build upon this work non-commercially, and license their derivative works on different terms, provided the original work is properly cited, appropriate credit is given, any changes made indicated, and the use is non-commercial. See: http://creativecommons.org/licenses/by-nc/4.0/. 